\title{
Standard dilution analysis of beverages by microwave-induced plasma optical emission spectrometry
}

\author{
Daniel A. Goncalves a , Tina McSweeney ${ }^{\text {b }}$, Mirian C. Santos ${ }^{\text {c }}$, Bradley T. Jones ${ }^{\text {d }}$, \\ George L. Donati ${ }^{\mathrm{d}, *}$ \\ a Department of Physics and Chemistry, UNESP-Univ Estadual Paulista, Av. Brasil, 56, Ilha Solteira, SP 15385-000, Brazil \\ ${ }^{\mathrm{b}}$ Agilent Technologies, 2500 Regency Parkway, Cary, NC 27518, USA \\ c Department of Analytical Chemistry, UNESP-Univ Estadual Paulista, R. Prof. Francisco Degni, 55, Quitandinha, Araraquara, SP 14800-060, Brazil \\ d Department of Chemistry, Wake Forest University, Salem Hall, Box 7486, Winston-Salem, NC 27109, USA
}

\section{H I G H L I G H T S}

- Only two calibration solutions for recoveries between 90 and $99 \%$.

- Accuracies comparable or even superior to traditional calibration methods.

- Simple sample dilution with $1 \% \mathrm{v} \mathrm{v}^{-1}$ $\mathrm{HNO}_{3}$.

- Less calibration points result in higher LODs.

- Internal standardization, matrix matching and in-line dilution.

\section{A R T I C L E I N F O}

\section{Article history:}

Received 10 July 2015

Received in revised form

16 December 2015

Accepted 17 December 2015

Available online 12 January 2016

\section{Keywords:}

Standard dilution analysis

Microwave-induced plasma

Matrix-matching

Calibration

Matrix effects

Beverages
G R A P H I C A L A B S T R A C T

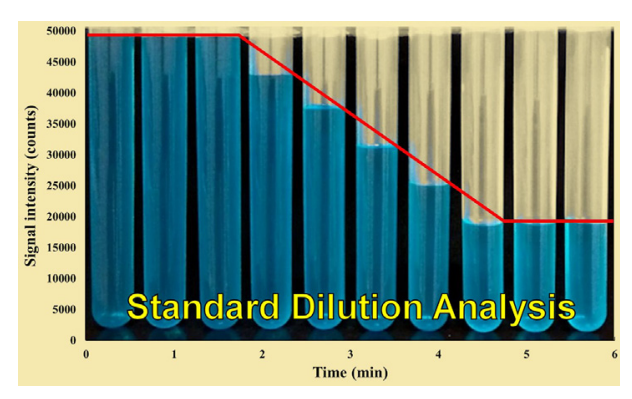

\section{A B S T R A C T}

In this work, standard dilution analysis (SDA) is combined with microwave-induced plasma optical emission spectrometry (MIP OES) to determine seven elements in coffee, green tea, energy drink, beer, whiskey and cachaça (Brazilian hard liquor). No sample preparation other than simple dilution in $\mathrm{HNO}_{3}$ $1 \% \mathrm{v} \mathrm{v}^{-1}$ is required. Due to relatively low plasma temperatures, matrix effects may compromise accuracies in MIP OES analyzes of complex samples. The method of standard additions (SA) offers enhanced accuracies, but is time-consuming and labor intensive. SDA offers a simpler, faster approach, with improved accuracies for complex matrices. In this work, SDA's efficiency is evaluated by spike experiments, and the results are compared to the traditional methods of external calibration (EC), internal standard (IS), and standard additions (SA). SDA is comparable to the traditional calibration methods, and it provides superior accuracies for applications involving ethanol-containing beverage samples. The SDAMIP OES procedure is effective. Using only two calibration solutions, it may be easily automated for accurate and high sample throughput routine applications.

(๑) 2016 Elsevier B.V. All rights reserved.

\footnotetext{
* Corresponding author.

E-mail address: donatigl@wfu.edu (G.L. Donati).
}

\section{Introduction}

Calibration is one of the most critical steps in any analytical procedure [1]. It usually requires several standard reference solutions, which can affect sample throughput. Ideally, these solutions 
should be prepared in the same medium as the sample to prevent matrix effects (i.e., matrix-matching). However, matching complex matrices such as beverages containing various amounts of alcohol is often an insurmountable challenge to the analyst.

For determinations involving simple matrices, accurate results may be achieved by employing external standard calibration (EC) and standard reference solutions prepared in a common solvent. This strategy is simple and efficient for most applications, but it can provide inaccurate results when combined with matrix-sensitive methods. On the other hand, poor accuracy caused by variations in sample viscosity and its effects on nebulization, sample transport and/or atomization can be minimized by employing the traditional method of internal standardization (IS) [2-4]. In IS, a species presenting physical-chemical properties similar to the analyte (i.e. an internal standard, IS) is added to blank, standard reference and sample solutions. The analyte-to-IS signal ratio is then used as the dependent variable ( $y$-axis) of the calibration curve. If the analyte and the IS experience the same fluctuations during the analysis, then using their signal ratio rather than the analytical signal alone can significantly improve accuracy and precision $[2,4]$. The main limitations of the IS method are related to its inability to correct for matrix effects and the difficulty to find ideal IS species for different applications.

For methods severely affected by matrix effects, standard additions (SA) is the most commonly used strategy to ensure reliable results [5-7]. By preparing the standard reference solutions using the sample as solvent, one can guarantee the same medium in all determinations. The analyte concentration in the sample is then determined by the $x$-axis intercept of the calibration curve. The SA method is one of the most efficient strategies to correct for rotational effects (i.e., variations in the analytical signal caused by concomitant species) [8] and it is widely used in all chemical analysis subfields [5-8]. On the other hand, SA is time-consuming and it becomes unpractical when analyzing several samples. In addition, it cannot correct for fluctuations in temperature, sample transport, nebulization and sample volume.

Standard dilution analysis (SDA) is a new method based on a different calibration approach. It combines SA and IS to simultaneously improve accuracy and sample throughput in complex matrix determinations [9]. Different from the traditional EC, IS and SA methods, only two solutions are required in SDA calibrations. Solution 1 contains $50 \%$ sample and $50 \%$ of a standard solution containing the analytes and an internal standard. Solution 2 has $50 \%$ sample and 50\% blank. Analyte and IS signals are continuously monitored and many calibration points are generated in "real time" as Solution 2 is added to the same tube containing Solution 1. Because the amount of sample never changes (both Solutions 1 and 2 contain each $50 \%$ sample), only the standards are diluted. This matrix-matching effect contributes to improved accuracies, and the presence of an IS minimizes signal fluctuations due to differences in sample viscosity $[9,10]$.

The SDA calibration curve is built by plotting the analyte-to-IS signal ratio on the $y$-axis, and the reciprocal of the IS concentration on the $x$-axis (i.e., $\mathrm{S}_{\mathrm{A}} / \mathrm{S}_{\mathrm{IS}}$ vs. $1 / \mathrm{C}_{\mathrm{IS}}$ ). Eqs. (1)-(4) show the mathematical treatment used to calculate the analyte concentration in the sample. The analytical signal $\left(\mathrm{S}_{\mathrm{A}}\right)$ arise from both the sample (sam) and the standard (std), while the IS signal ( $\left.\mathrm{S}_{\mathrm{IS}}\right)$ comes from the standard only. These signals are related to the respective concentrations by the calibration curve sensitivities $(\mathrm{m}): \mathrm{S}_{\mathrm{A}}=\mathrm{m}_{\mathrm{A}} \mathrm{C}_{\mathrm{A}}$ and $\mathrm{S}_{\mathrm{IS}}=\mathrm{m}_{\mathrm{IS}} \mathrm{C}_{\mathrm{IS}}$. By taking the analyte-to-IS signal ratio, $\mathrm{S}_{\mathrm{A}} / \mathrm{S}_{\mathrm{IS}}$ :

$\frac{S_{A}}{S_{I S}}=\frac{m_{A} C_{A}}{m_{I S} C_{I S}}=\frac{m_{A}\left(C_{A}^{\text {sam }}+C_{A}^{s t d}\right)}{m_{I S} C_{I S}}=\frac{m_{A} C_{A}^{s a m}}{m_{I S} C_{I S}}+\frac{m_{A} C_{A}^{s t d}}{m_{I S} C_{I S}}$

If we consider $S_{A} / S_{I S}$ as the dependent variable $\left(y\right.$-axis) and $1 / C_{I S}$ as the independent variable ( $x$-axis), the slope and intercept of this calibration curve will be:

$$
\begin{gathered}
\text { Slope }=\frac{m_{A} C_{A}^{\text {sam }}}{m_{I S}} \\
\text { Intercept }=\frac{m_{A} C_{A}^{s t d}}{m_{I S} C_{I S}}
\end{gathered}
$$

Finally, the analyte concentration in the sample is calculated from the values of slope and intercept by rearranging Eqs. (2) and (3):

$C_{A}^{\text {sam }}=\frac{\text { Slope }}{\text { Intercept }} \times \frac{C_{A}^{\text {std }}}{C_{I S}}$

The efficiency of the SDA method at improving accuracy and sample throughput has recently been demonstrated for UV-VIS molecular absorption spectroscopy and inductively coupled plasma optical emission spectrometry (ICP OES) [9]. Considering complex samples and the potential matrix effects in a relatively low temperature (ca. $5000 \mathrm{~K}$ ) microwave-induced plasma (MIP) [11], the SDA method is an interesting alternative to SA in MIP OES applications. In the present work, we combine SDA with the plasma stability of MIP OES to determine seven elements in beverage samples. The $\mathrm{N}_{2}$ MIP is tolerant to high solvent loads [12,13], which allows for a sample preparation procedure based on simple dilution with $\mathrm{HNO}_{3} 1 \% \mathrm{v} \mathrm{v}^{-1}$. Complex matrix samples of coffee, green tea, energy drink, beer, whiskey and cachaça (Brazilian hard liquor) are analyzed by SDA-MIP OES and the results are compared with values obtained with the traditional methods of EC, IS and SA.

\section{Experimental}

\subsection{Instrumentation}

An Agilent 4200 MP-AES (Agilent Technologies, Santa Clara, CA, USA) was used in all determinations. The sample introduction system is composed of a SPS 3 automatic sampler, solvent-resistant tubing, a double-pass cyclonic spray chamber and the inert OneNeb nebulizer. A liquid $\mathrm{N}_{2}$ Dewar was used as plasma gas source. The same nebulization gas flow rate and plasma observation position were used for all analytes in SDA determinations: $0.75 \mathrm{~L} \mathrm{~min}^{-1}$ and 0 , respectively. The plasma observation position is based on stepper motor positions and has no specific unit. In this case, 0 approximately corresponds to the center of the plasma.

Because the $4200 \mathrm{MP}-\mathrm{AES}$ collects data sequentially (i.e., one wavelength at the time), we have used the optimization feature in the MP Expert software for all SDA determinations. This feature is used in common applications to define the best conditions of nebulization gas flow rate and plasma observation position for each individual analyte. In SDA, it allows for continuous, multi-element and real-time signal acquisition (SDA's main requirements). The sequentially recorded emission signals are then exported as CSV files for MS Excel data processing.

For comparison, all analytes were also determined by the traditional methods of EC, IS and SA. Depending on the sample matrix, either aqueous or ethanolic multi-element solutions were used to determine the best conditions (Tables 1 and 2) for each analyte and the internal standard (yttrium). In this case, the instrument's normal acquisition mode was used to determine $\mathrm{Al}, \mathrm{Co}$, $\mathrm{Cr}, \mathrm{Cu}, \mathrm{Mn}, \mathrm{Ni}$ and $\mathrm{Zn}$ in six beverage samples. 
Table 1

Operating conditions for the direct analysis of beverage samples by MIP OES.

\begin{tabular}{lll}
\hline Instrumental parameter & Acquisition Mode & \\
\cline { 2 - 3 } & Normal $^{\mathrm{a}}$ & Continuous $^{\mathrm{b}}$ \\
\hline Integration time (s) & 3 & 1 \\
Peristaltic pump speed (rpm) & 15 & 7 \\
Number of replicates & 3 & 1 \\
Stabilization time (s) & 15 & 0 \\
Background correction & Auto & None \\
\hline
\end{tabular}

a Normal acquisition mode: used in EC, IS and SA determinations.

b Continuous real-time acquisition mode: used in SDA determinations.

Table 2

MIP OES nebulization gas flow rates and plasma observation positions used in EC, IS and SA determinations.

\begin{tabular}{llllllc}
\hline Element & Wavelength $(\mathrm{nm})$ & \multicolumn{2}{l}{$\begin{array}{l}\text { Nebulization gas flow } \\
\text { rate }\left(\mathrm{L} \mathrm{min}^{-1}\right)\end{array}$} & & \multicolumn{2}{l}{ Observation position } \\
\cline { 3 - 4 } \cline { 6 - 7 } & & Aqueous & Ethanolic & & Aqueous & Ethanolic \\
\hline $\mathrm{Al}$ & 396.152 & 1.00 & 1.00 & & -10 & 0 \\
$\mathrm{Co}$ & 340.512 & 0.80 & 0.85 & & -10 & -10 \\
$\mathrm{Cr}$ & 425.433 & 1.00 & 1.00 & & -10 & -10 \\
$\mathrm{Cu}$ & 324.754 & 0.80 & 0.80 & & -10 & 0 \\
$\mathrm{Mn}$ & 403.076 & 0.95 & 1.00 & & -20 & 0 \\
$\mathrm{Ni}$ & 341.476 & 0.80 & 0.85 & & 0 & 0 \\
$\mathrm{Y}^{\mathrm{a}}$ & 371.029 & 0.75 & 0.75 & & 0 & 0 \\
$\mathrm{Zn}$ & 213.857 & 0.50 & 0.55 & & 10 & 10 \\
\hline
\end{tabular}

a Internal standard.

\subsection{Standard reference solutions, samples and sample preparation}

Distilled-deionized water (18 M $\Omega \mathrm{cm}$, Milli-Q ${ }^{\circledR}$, Millipore, Bedford, MA, USA) and trace metal grade nitric acid (Fisher, Pittsburgh, PA, USA) were used to prepare all working solutions used in this work. Single-element stock solutions containing $1000 \mathrm{mg} \mathrm{L}^{-1}$ of $\mathrm{Al}, \mathrm{Co}, \mathrm{Cr}, \mathrm{Cu}, \mathrm{Mn}, \mathrm{Ni}, \mathrm{Y}$ or Zn (SPEX CertPrep, Metuchen, NJ, USA) were used to prepare standard reference solutions and to carry out spike experiments.

Coffee, green tea, energy drink, beer (4.4\% $\mathrm{v} \mathrm{v}^{-1}$ ethanol), whiskey ( $40 \% \mathrm{v} \mathrm{v}^{-1}$ ethanol) and cachaça (Brazilian hard liquor, $40 \%$ $\mathrm{v} \mathrm{v}^{-1}$ ethanol) were filtered with filter paper $(0.45-\mu \mathrm{m}$ pore size) and diluted 4-fold with $\mathrm{HNO}_{3} 1 \% \mathrm{v} \mathrm{v}^{-1}$. To replicate common coffee and green tea preparations, these samples were brewed in-lab with tap water before filtration and dilution. For SDA, $2.5 \mathrm{~mL}$ of sample $+2.5 \mathrm{~mL}$ of a standard solution ( $\mathrm{Al}, \mathrm{Cr}, \mathrm{Cu}, \mathrm{Mn}$ and $\mathrm{Y}$ $2.00 \mathrm{mg} \mathrm{L}^{-1}$; $\mathrm{Co}$, Ni and $\mathrm{Zn} 5.00 \mathrm{mg} \mathrm{L}^{-1}$ ) were transferred to a polypropylene tube (Solution 1 ). Solution 2 was prepared by mixing $2.5 \mathrm{~mL}$ of sample $+2.5 \mathrm{~mL}$ of $\mathrm{HNO}_{3} 1 \% \mathrm{v} \mathrm{v}^{-1}$ into another tube. During analysis, Solution 2 was poured into the same tube containing Solution 1 to produce the SDA calibration curves. Spike experiments were carried out with all samples to evaluate the method's accuracy. The traditional calibration methods of EC, IS and SA were applied to the same samples and spike experiments for comparison.

\section{Results and discussion}

\subsection{SDA calibration and typical signal profiles}

As Solution 1 is introduced into the plasma, the continuously recorded analytical signals rise until they reach a plateau. When Solution 2 is poured into the same tube containing Solution 1, analytes and IS in the standard are diluted, and a negative signal slope is produced. The many calibration points on this slope are then used for SDA calibration. Fig. 1 shows typical SDA signal profiles and their corresponding calibration curves. The $x$-axis values in Fig. $1 \mathrm{~b}\left(1 / \mathrm{C}_{\mathrm{IS}}\right)$ are calculated from the maximum yttrium signal (at the plateau) and the corresponding known Y concentration in Solution 1 [9]. In this case, one considers a linear relationship between signal intensity and analyte concentrations during the dilution.

\subsection{Powers of detection}

The limits of detection (LOD) and quantification (LOQ) for determinations using SDA and MIP OES were determined and compared to values obtained with the traditional method of EC. The LODs were calculated according to IUPAC's recommendations as 3 times the standard deviation of the blank signal $\left(S_{B}\right)$ divided by the calibration curve slope $(\mathrm{m})$ : $\mathrm{LOD}=3 \mathrm{~S}_{\mathrm{B}} / \mathrm{m}$. For SDA, the LODs were calculated as 3 times the blank equivalent concentration $\left(C_{B}\right)$ : LOD $=3 C_{B}$. In this case, a $1 \% \mathrm{v} \mathrm{v}^{-1} \mathrm{HNO}_{3}$ solution was used as sample and the concentrations found using the SDA method were multiplied by 3 to calculate the LODs. The LOQs were calculated in the same manner, with 10 replacing 3 in each equation, i.e., $\mathrm{LOQ}=10 \mathrm{~S}_{\mathrm{B}} / \mathrm{m}$; or $\mathrm{LOQ}=10 \mathrm{C}_{\mathrm{B}}$. In all cases, 10 consecutive blank solution measurements were used to calculate both LOD and LOQ. Table 3 presents the results for all calibration methods evaluated. For comparison purposes, the instrumental LODs and LOQs calculated for EC are assumed to be similar to values one would obtain for IS and SA. It is important to note that lower LODs can be obtained when using the manufacturer's recommended operating conditions.

Ideally, analytical signals must be collected simultaneously and in real time in SDA [9]. Because the MIP OES used in this work is a sequential instrument, there is a small delay between measurements at each wavelength. The number of points on a SDA calibration curve depends on both the standard dilution time frame and the instrument's acquisition speed. Thus, the small delay between analytical lines will result in fewer calibration points, which may compromise precision and accuracy. In the present work, we have established three conditions to increase the number of SDA calibration points: $(i)$ all elements were determined at the same conditions (same nebulization gas flow rate and plasma observation position); (ii) only 4-5 elements were monitored at the time; and (iii) the lowest integration time available was employed (1 s).

Although important to increase the number of SDA calibration points, some of these instrumental conditions contribute to the higher LODs observed in Table 3. In addition to the small integration time, the analytes are not determined at their optimal nebulization gas flow rates and plasma observation positions. Another important factor contributing to SDA's lower powers of detection is related to background (BG) correction. The analytical signals obtained with the software optimization feature used in SDA determinations are not BG-corrected, and blank subtraction is the only strategy available to minimize BG effects. Thus, relative high blank signals may negatively affect the LODs (e.g. Zn in Table 3). These results are in disagreement with what was observed in ICP OES determinations, where the SDA LODs were lower than the ones obtained with the traditional calibration methods [9]. In SDA, the more calibration points the higher the precision, the lower the noise and the better the LODs. Therefore, the better performance observed for ICP OES can be associated with both the large amount of calibration points obtained in simultaneous determinations and a more adequate background correction.

\subsection{Accuracy}

Complex samples, especially those with potential to produce severe matrix effects in MIP OES determinations, were chosen to 

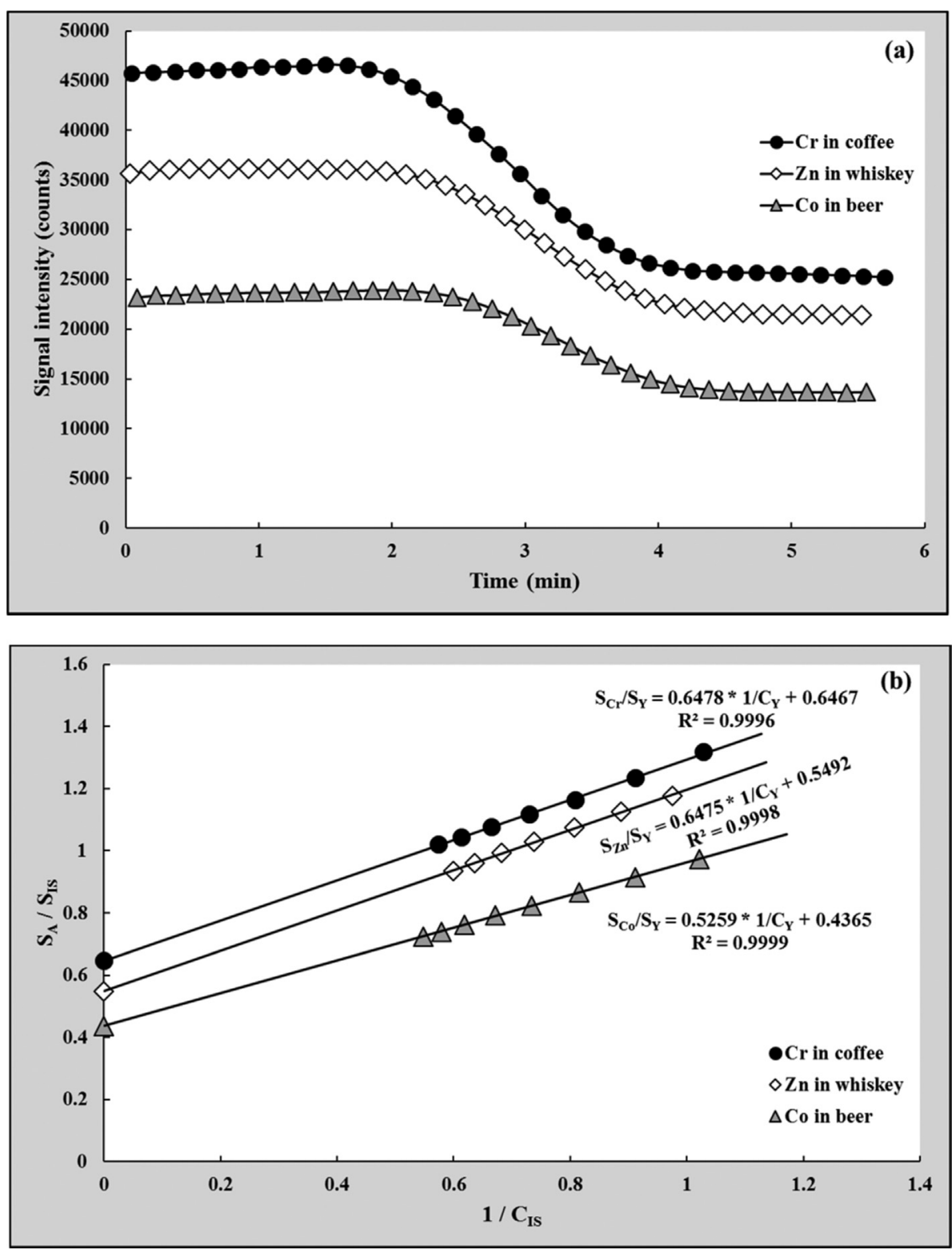

Fig. 1. SDA signal profiles (a) and their corresponding calibration curves (b) for the determination of $\mathrm{Cr}$ in coffee, $\mathrm{Zn}$ in whiskey, and Co in beer.

Table 3

Instrumental limits of detection (LOD) and quantification (LOQ), in $\mu \mathrm{g} \mathrm{L}^{-1}$, for MIP OES determinations using SDA and EC.

\begin{tabular}{|c|c|c|c|c|c|}
\hline \multirow[t]{2}{*}{ Element } & \multirow[t]{2}{*}{ Wavelength (nm) } & \multicolumn{2}{|l|}{$\mathrm{SDA}^{\mathrm{a}}$} & \multicolumn{2}{|l|}{$\mathrm{EC}^{\mathrm{b}}$} \\
\hline & & LOD & LOQ & LOD & LOQ \\
\hline $\mathrm{Al}$ & 396.152 & 20 & 50 & 6 & 20 \\
\hline Co & 340.512 & 100 & 300 & 20 & 60 \\
\hline $\mathrm{Cr}$ & 425.433 & 40 & 100 & 10 & 40 \\
\hline $\mathrm{Cu}$ & 324.754 & 10 & 40 & 6 & 20 \\
\hline Mn & 403.076 & 30 & 100 & 40 & 100 \\
\hline $\mathrm{Ni}$ & 341.476 & 40 & 100 & 7 & 20 \\
\hline $\mathrm{Zn}$ & 213.857 & 500 & 2000 & 400 & 1000 \\
\hline
\end{tabular}

a Integration time $=1 \mathrm{~s}$.

b Integration time $=3 \mathrm{~s}$.

evaluate SDA's accuracy. Coffee, green tea, energy drink, beer, whiskey and cachaça (a Brazilian sugarcane hard liquor) were spiked with all analytes and the concentrations were determined by SDA-MIP OES. For comparison, the same samples were analyzed using EC, IS and SA. Table 4 shows the results. Percent recoveries and the corresponding averages for each calibration method are presented in Table 5. As it can be seen, accuracies for SDA and the traditional calibration methods are comparable. SDA may even provide superior recoveries for ethanol-containing matrices. Similar to what was previously observed for UV-Vis molecular absorption spectroscopy and ICP OES [9], SDA's combination of internal standardization and matrix-matching allows for precise and accurate determinations. As the data in Tables 4 and 5, and previously published results suggest [9], SDA is adequate for applications using both simultaneous and sequential signal acquisition.

The SDA method was also applied to diluted aliquots of the original samples (i.e., with no spike). In most cases, analyte concentrations were below the LOQs. Cobalt, for example, was only found in whiskey and cachaça: $4.33 \pm 0.05$ and $3.41 \pm 0.03 \mathrm{mg} \mathrm{L}^{-1}$, respectively. Aluminum varied from $0.24 \pm 0.01 \mathrm{mg} \mathrm{L}^{-1}$ in cachaça 
Table 4

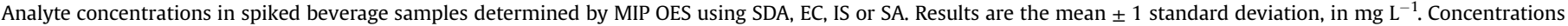
added: $\mathrm{Al}, \mathrm{Cr}, \mathrm{Cu}$ and $\mathrm{Mn} 1.00 \mathrm{mg} \mathrm{L}^{-1}$; $\mathrm{Co}$, Ni and $\mathrm{Zn} 3.00 \mathrm{mg} \mathrm{L}^{-1}$.

\begin{tabular}{|c|c|c|c|c|c|c|c|c|}
\hline Sample & Method & $\mathrm{Al}$ & Co & $\mathrm{Cr}$ & $\mathrm{Cu}$ & $\mathrm{Mn}^{\mathrm{a}}$ & $\mathrm{Ni}$ & $\mathrm{Zn}$ \\
\hline \multirow[t]{4}{*}{ Coffee } & SDA & $1.02 \pm 0.06$ & $2.96 \pm 0.06$ & $0.98 \pm 0.03$ & $0.97 \pm 0.05$ & $0.83 \pm 0.02$ & $3.05 \pm 0.15$ & $3.04 \pm 0.28$ \\
\hline & EC & $0.93 \pm 0.01$ & $2.84 \pm 0.03$ & $0.90 \pm 0.01$ & $0.98 \pm 0.01$ & $2.81 \pm 0.02$ & $2.89 \pm 0.02$ & $3.00 \pm 0.04$ \\
\hline & IS & $1.01 \pm 0.01$ & $3.21 \pm 0.03$ & $1.07 \pm 0.01$ & $0.97 \pm 0.01$ & $3.33 \pm 0.02$ & $3.46 \pm 0.01$ & $2.35 \pm 0.05$ \\
\hline & SA & $0.89 \pm 0.01$ & $3.04 \pm 0.03$ & $0.88 \pm 0.01$ & $0.96 \pm 0.01$ & $3.32 \pm 0.03$ & $3.19 \pm 0.04$ & $3.45 \pm 0.01$ \\
\hline \multirow[t]{4}{*}{ Green tea } & SDA & $0.90 \pm 0.12$ & $2.70 \pm 0.19$ & $0.92 \pm 0.07$ & $1.05 \pm 0.03$ & $1.03 \pm 0.12$ & $3.06 \pm 0.11$ & $3.03 \pm 0.29$ \\
\hline & $\mathrm{EC}$ & $1.10 \pm 0.01$ & $2.87 \pm 0.02$ & $1.02 \pm 0.01$ & $1.08 \pm 0.01$ & $1.04 \pm 0.01$ & $2.86 \pm 0.01$ & $3.02 \pm 0.01$ \\
\hline & IS & $1.35 \pm 0.01$ & $3.14 \pm 0.03$ & $1.12 \pm 0.01$ & $1.35 \pm 0.01$ & $1.14 \pm 0.01$ & $3.17 \pm 0.01$ & $3.44 \pm 0.04$ \\
\hline & SA & $1.01 \pm 0.05$ & $2.79 \pm 0.04$ & $1.04 \pm 0.01$ & $1.19 \pm 0.01$ & $1.01 \pm 0.01$ & $3.18 \pm 0.04$ & $3.64 \pm 0.21$ \\
\hline \multirow[t]{4}{*}{ Energy drink } & SDA & $1.00 \pm 0.01$ & $2.75 \pm 0.20$ & $0.95 \pm 0.02$ & $1.01 \pm 0.02$ & $1.01 \pm 0.02$ & $3.06 \pm 0.22$ & $3.19 \pm 0.25$ \\
\hline & $\mathrm{EC}$ & $0.99 \pm 0.01$ & $2.83 \pm 0.01$ & $1.00 \pm 0.01$ & $1.09 \pm 0.01$ & $0.98 \pm 0.01$ & $2.83 \pm 0.01$ & $3.04 \pm 0.01$ \\
\hline & IS & $1.40 \pm 0.01$ & $2.56 \pm 0.02$ & $1.25 \pm 0.01$ & $1.40 \pm 0.01$ & $1.24 \pm 0.01$ & $3.56 \pm 0.01$ & $3.77 \pm 0.04$ \\
\hline & SA & $1.12 \pm 0.02$ & $4.12 \pm 0.08$ & $1.05 \pm 0.01$ & $1.13 \pm 0.01$ & $1.08 \pm 0.02$ & $3.42 \pm 0.02$ & $3.60 \pm 0.53$ \\
\hline \multirow[t]{4}{*}{ Beer } & SDA & $0.95 \pm 0.01$ & $2.88 \pm 0.12$ & $0.89 \pm 0.04$ & $1.05 \pm 0.02$ & $0.98 \pm 0.01$ & $2.80 \pm 0.06$ & $3.19 \pm 0.24$ \\
\hline & $\mathrm{EC}$ & $1.24 \pm 0.01$ & $3.12 \pm 0.01$ & $1.16 \pm 0.01$ & $1.15 \pm 0.01$ & $1.13 \pm 0.01$ & $3.11 \pm 0.01$ & $3.46 \pm 0.01$ \\
\hline & IS & $1.27 \pm 0.01$ & $3.21 \pm 0.01$ & $1.18 \pm 0.01$ & $1.27 \pm 0.01$ & $1.16 \pm 0.01$ & $3.19 \pm 0.01$ & $3.56 \pm 0.03$ \\
\hline & SA & $1.19 \pm 0.02$ & $2.53 \pm 0.08$ & $1.28 \pm 0.01$ & $1.22 \pm 0.01$ & $1.22 \pm 0.02$ & $3.64 \pm 0.02$ & $3.65 \pm 0.53$ \\
\hline \multirow[t]{4}{*}{ Whiskey } & SDA & $0.95 \pm 0.07$ & $2.72 \pm 0.06$ & $0.79 \pm 0.02$ & $0.85 \pm 0.02$ & $0.91 \pm 0.04$ & $2.70 \pm 0.09$ & $2.94 \pm 0.11$ \\
\hline & $\mathrm{EC}$ & $1.22 \pm 0.01$ & $3.41 \pm 0.01$ & $1.26 \pm 0.01$ & $1.25 \pm 0.01$ & $1.24 \pm 0.01$ & $3.24 \pm 0.01$ & $4.05 \pm 0.03$ \\
\hline & IS & $0.99 \pm 0.01$ & $2.77 \pm 0.02$ & $1.02 \pm 0.01$ & $0.99 \pm 0.01$ & $1.01 \pm 0.01$ & $2.75 \pm 0.02$ & $3.27 \pm 0.03$ \\
\hline & SA & $1.01 \pm 0.05$ & $3.45 \pm 0.04$ & $1.03 \pm 0.01$ & $1.04 \pm 0.01$ & $0.93 \pm 0.01$ & $3.19 \pm 0.04$ & $3.56 \pm 0.21$ \\
\hline \multirow[t]{4}{*}{ Cachaça } & SDA & $0.92 \pm 0.02$ & $3.13 \pm 0.08$ & $0.72 \pm 0.01$ & $0.88 \pm 0.02$ & $0.93 \pm 0.01$ & $2.70 \pm 0.05$ & $3.13 \pm 0.08$ \\
\hline & $\mathrm{EC}$ & $1.21 \pm 0.01$ & $3.33 \pm 0.01$ & $1.23 \pm 0.01$ & $1.27 \pm 0.01$ & $1.42 \pm 0.01$ & $3.36 \pm 0.01$ & $3.81 \pm 0.05$ \\
\hline & IS & $0.95 \pm 0.01$ & $2.47 \pm 0.01$ & $0.98 \pm 0.01$ & $2.47 \pm 0.01$ & $1.11 \pm 0.01$ & $2.66 \pm 0.01$ & $3.13 \pm 0.01$ \\
\hline & SA & $1.08 \pm 0.01$ & $3.84 \pm 0.08$ & $1.12 \pm 0.01$ & $1.26 \pm 0.01$ & $1.05 \pm 0.01$ & $3.38 \pm 0.06$ & $2.75 \pm 0.08$ \\
\hline
\end{tabular}

a Spike concentration for Mn in coffee is $3.00 \mathrm{mg} \mathrm{L}^{-1}$ for EC, IS and SA.

Table 5

Percent recoveries (\%) for spike experiments with 7 analytes in different beverage samples as determined by the MIP OES using SDA, EC, IS or SA.

\begin{tabular}{|c|c|c|c|c|c|c|c|c|c|}
\hline Sample & Method & $\mathrm{Al}$ & Co & $\mathrm{Cr}$ & $\mathrm{Cu}$ & $\mathrm{Mn}$ & $\mathrm{Ni}$ & $\mathrm{Zn}$ & Average \\
\hline \multirow[t]{4}{*}{ Coffee } & SDA & 102 & 99 & 98 & 97 & 83 & 102 & 101 & 97 \\
\hline & EC & 93 & 94 & 90 & 98 & 94 & 96 & 100 & 95 \\
\hline & IS & 101 & 107 & 107 & 97 & 111 & 115 & 78 & 102 \\
\hline & SA & 89 & 102 & 88 & 96 & 111 & 106 & 115 & 101 \\
\hline \multirow[t]{4}{*}{ Green tea } & SDA & 90 & 90 & 92 & 105 & 103 & 102 & 101 & 98 \\
\hline & $\mathrm{EC}$ & 110 & 96 & 102 & 108 & 104 & 95 & 101 & 102 \\
\hline & IS & 135 & 104 & 112 & 135 & 114 & 106 & 115 & 117 \\
\hline & SA & 100 & 126 & 104 & 119 & 101 & 106 & 121 & 111 \\
\hline \multirow[t]{4}{*}{ Energy drink } & SDA & 100 & 92 & 95 & 100 & 101 & 102 & 106 & 99 \\
\hline & $\mathrm{EC}$ & 99 & 94 & 100 & 109 & 98 & 94 & 101 & 99 \\
\hline & IS & 140 & 118 & 125 & 140 & 124 & 119 & 126 & 127 \\
\hline & SA & 112 & 137 & 105 & 113 & 108 & 114 & 120 & 116 \\
\hline \multirow[t]{4}{*}{ Beer } & SDA & 105 & 95 & 96 & 89 & 98 & 93 & 107 & 98 \\
\hline & $\mathrm{EC}$ & 115 & 124 & 104 & 116 & 113 & 104 & 115 & 113 \\
\hline & IS & 127 & 127 & 107 & 118 & 116 & 106 & 119 & 117 \\
\hline & SA & 122 & 119 & 118 & 128 & 122 & 121 & 122 & 122 \\
\hline \multirow[t]{4}{*}{ Whiskey } & SDA & 95 & 91 & 79 & 85 & 91 & 90 & 98 & 90 \\
\hline & $\mathrm{EC}$ & 122 & 114 & 126 & 125 & 124 & 108 & 135 & 122 \\
\hline & IS & 99 & 92 & 102 & 99 & 101 & 92 & 109 & 99 \\
\hline & SA & 101 & 115 & 103 & 104 & 93 & 106 & 119 & 106 \\
\hline \multirow[t]{4}{*}{ Cachaça } & SDA & 92 & 104 & 72 & 88 & 92 & 90 & 103 & 92 \\
\hline & $\mathrm{EC}$ & 121 & 111 & 123 & 127 & 142 & 112 & 127 & 123 \\
\hline & IS & 95 & 82 & 98 & 82 & 111 & 89 & 104 & 94 \\
\hline & SA & 108 & 128 & 112 & 126 & 105 & 113 & 92 & 112 \\
\hline
\end{tabular}

to $7.60 \pm 0.06 \mathrm{mg} \mathrm{L}^{-1}$ in green tea. Copper and $\mathrm{Mn}$ concentrations were in the ranges $0.30-1.84$ and $0.67-2.89 \mathrm{mg} \mathrm{L}^{-1}$, respectively. All values for $\mathrm{Cr}$, $\mathrm{Ni}$ and $\mathrm{Zn}$ were below the LOQs.

\section{Conclusions}

Because of the sequential signal acquisition nature of the MIP OES, fewer SDA calibration points are obtained when compared to ICP OES determinations, which results in higher LODs. On the other hand, the method's accuracy is comparable to, and for some ethanol-containing samples even better than, the ones obtained with the traditional calibration methods. SDA average recoveries for several elements in all samples evaluated in this work were between 90 and 99\%. For the traditional method of standard additions, for example, average recoveries between 101 and 122\% were obtained for the same analytes and samples.

By combining the internal standardization and matrix-matching capabilities of SDA with the plasma stability of MIP OES, it is possible to accurately analyze complex-matrix beverage samples with virtually no sample preparation. The SDA-MIP OES method with only two calibration solutions is simple, efficient and may easily be automated for high sample throughput routine applications.

\section{Acknowledgments}

The authors would like to thank Agilent Technologies and Wake Forest University for their support to this work. The fellowship provided to D. A. G. by the Coordenação de Aperfeiçoamento de Pessoal de Nível Superior (CAPES, Brazil, Grant No 99999.002566/ 2014-01) is also greatly appreciated.

\section{References}

[1] H. Mark, Principles and practice of spectroscopic calibration, in: first ed., in: J.D. Winefordner, I.M. Kolthoff (Eds.), Chemical Analysis: a Series of Monographs on Analytical Chemistry and its Applications, vol. 118, Wiley-Interscience, New York, 1991, p. 192.

[2] G.A. Zachariadis, C. Vogiatzis, An overview of the use of yttrium for internal standardization in inductively coupled plasma-atomic emission spectrometry, Appl. Spectrosc. Rev. 45 (2010) 220-239.

[3] H. Veening, Quantitative infrared analysis of xylene mixtures: internal standard method, J. Chem. Educ. 43 (1966) 319-320.

[4] M.A. Bechlin, F.M. Fortunato, E.C. Ferreira, J.A. Gomes Neto, J.A. Nóbrega, G.L. Donati, B.T. Jones, Bismuth as a general internal standard for lead in atomic absorption spectrometry, Anal. Chim. Acta 831 (2014) 24-30.

[5] W.R. Kelly, K.W. Pratt, W.F. Guthrie, K.R. Martin, Origin and early history of Die Methode des Eichzusatzes or The Method of Standard Addition, with primary emphasis on its origin, early design, dissemination, and usage of terms, Anal. Bioanal. Chem. 400 (2011) 1805-1812.

[6] M. Bader, A systematic approach to standard addition methods in instrumental analysis, J. Chem. Educ. 57 (1980) 703-706.

[7] D.T. Harvey, External standards or standard addition? Selecting and validating 
a method of standardization, J. Chem. Educ. 79 (2002) 613-615.

[8] Analytical Methods Committee, in: M. Thompson (Ed.), Standard Additions: Myth and Reality, vol.37, AMC Tech. Briefs, 2009, pp. 1-2.

[9] W.B. Jones, G.L. Donati, C.P. Calloway Jr., B.T. Jones, Standard dilution analysis, Anal. Chem. 87 (2015) 2321-2327.

[10] F.M. Fortunato, M.A. Bechlin, J.A. Gomes Neto, G.L. Donati, B.T. Jones, Internal standard addition calibration: determination of calcium and magnesium by atomic absorption spectrometry, Microchem. J. 122 (2015) 63-69.

[11] J. Jankowski, E. Reszke, Microwave Induced Plasma Analytical Spectrometry, first ed., RSC Publishing, Cambridge, 2011, p. 264.

[12] G.L. Donati, R.S. Amais, D. Schiavo, J.A. Nóbrega, Determination of Cr, Pb, $\mathrm{Ni}$ and $\mathrm{V}$ in gasoline and ethanol fuel by microwave plasma optical emission spectrometry, J. Anal. At. Spectrom. 28 (2013) 755-759.

[13] R.S. Amais, G.L. Donati, D. Schiavo, J.A. Nóbrega, A simple dilute-and-shoot procedure for $\mathrm{Si}$ determination in diesel and biodiesel by microwaveinduced plasma optical emission spectrometry, Microchem. J. 106 (2013) $318-322$. 